\title{
Perceived stressors of undergraduate dental students at an Australasian dental school
}

\author{
Siddharth Garde ${ }^{1,2}$, Lee A Adam², Andrew Tawse-Smith²* \\ 1 University of Sydney School of Dentistry, Faculty of Medicine and Health, NSW, Australia \\ ${ }^{2}$ Sir John Walsh Research Institute, Faculty of Dentistry, University of Otago, Dunedin, New Zealand
}

\begin{abstract}
The purpose of this study was to identify the perceived stressors of Bachelor of Dental Surgery (BDS) students at a prominent Australasian dental school using the Dental Environment Stress (DES) questionnaire. All BDS students were emailed a modified version of the DES questionnaire. The questionnaire consisted of forty questions: seven collecting demographic information, one free text question and thirty-two items related to various sources of stress, grouped into four subscales: 1) Academic 2) Clinical and patient related 3) Environmental and 4) Personal. Students were asked to rate the items on a five-point Likert-type scale ranging from not at all stressful (1) to extremely stressful (5). Of the 314 students emailed, 165 responded to the survey $(52.5 \%$ response rate). The academic subscale had the highest self-reported mean stress score $(3.09 \pm 0.68$ (SD); compared with the clinical $(2.71 \pm$ $0.77)$, environmental $(2.40 \pm 0.77)$ and personal $(2.37 \pm 0.68)$ subscales. There was a statistically significant difference $(\mathrm{p}<0.05)$ in self-perceived clinic related stress levels between male and female students, with female students reporting more stress. There was also a statistically significant difference in selfperceived environmental stress between second- and third-year students $(\mathrm{p}=0.037)$, and in perceived personal stress between students based on their English language status $(p=0.034)$. These findings can enable identification of students who might be at higher risk of stress to ensure support is provided for them; specifically, female students and students in their third year. Results also indicate the need to develop interventions to help all students with academic stressors.
\end{abstract}

Keywords: perceived stress, dental students, dental education, student experience, clinical education

\section{Introduction}

The term "stress" is now well embedded in our vocabulary, even though it only originated approximately sixty years ago (Al-Sowygh, 2013). The word has a variable meaning depending on the situation and the
Received:

22 June 2021

Revised:

27 July 2021

Accepted:

28 July 2021

Published Online:

31 July 2021

\section{How to cite this article:}

Garde, S. ., Adam, L. A., \& TawseSmith, A. (2021). Perceived stressors of undergraduate dental students at an Australasian dental school. IIUM Journal of Orofacial and Health Sciences, 2(2), 107-119. Retrieved from https://doi.org/10.31436/ijohs. $\underline{\mathrm{v} 2 \mathrm{i} 2.99}$

\section{Article DOI:}

https://doi.org/10.31436/ijohs. v2i2.99

\section{*Corresponding author}

Address:

Department of Oral Sciences, School of Dentistry, University of Otago, 310 Great King Street PO Box 56, Dunedin 9016, New Zealand

Telephone:

+64-3-4703589

Email address:

andrew.tawse-smith@otago.ac.nz 
example, there is a significant difference in reported stress levels between undergraduate dental students and their medical counterparts, with the dental cohort reporting greater stress levels (Al-Sowygh, 2013; Fonseca et al., 2013). Research reports that dental students' levels of depression, anxiety and hostility are near the levels expected for psychiatric outpatients (AbuGhazaleh et al., 2011; Morse \& Dravo, 2007). This may be because dental education is known as one of the most difficult and stressful fields of study, (Muirhead \& Locker, 2008; Polychronopoulou \& Divaris, 2009) not least because dental students are required to gain and develop a myriad of clinical, academic and interpersonal skills (Polychronopoulou \& Divaris, 2009). A systematic review found a correlation between medical students' perceptions of stress and their risk of future depression. Whether the stress experiences of dental students indicate their stress levels as a working dentists is not yet known, and this has been indicated as an area for future research (Pau et al., 2007). Students' stress is a major concern for dental educators. Increased stress may lead to a decrease in students' performance (Kumar et al., 2009) which may lead to attrition or failing. There is a significant expense involved in training healthcare professionals; therefore, attrition has a substantial financial impact as well as hindering the well-being of students (Birks et al., 2009).

There are certain demographic trends that can be identified regarding dental students and their perceived stress. There is evidence of a correlation between higher levels of dental education (i.e. clinical training) and stress (Harikiran et al., 2012). First choice of admission into dentistry (rather than as a fall-back option) has also been shown to have a relationship with stress levels in dental students (Pau et al., 2007). Other demographic trends include correlations between students' perceived stress levels and their emotional intelligence, previous higher education and gender (Polychronopoulou \& Divaris, 2009). It should be noted that gender is a controversial topic when it comes to dental education and stress, and this will be discussed in greater detail later in this paper.

Country of study is another factor that may impact on students' stress. A multi-country study of dental students' perceived sources of stress found that individual perceived stressors varied considerably amongst students from different dental schools. Greek and Spanish students appeared most stressed about their professional future, whereas Swedish and Irish students were more stressed about clinical issues such as patients being late or not showing up for appointments (Polychronopoulou \& Divaris, 2009). However, it should be taken into consideration that these results may be due to differences between dental schools rather than differences between country of study.

The purpose of the current study was to identify the perceived stressors of undergraduate dental students at an Australasian dental school and identify if any groups reported more stress than others. The results of this study may help researchers and dental educators within Australasia, and perhaps internationally, better analyse the factors surrounding stressors of dental students. This will help inform management strategies to reduce burnout and to bring out the best of the students' abilities in a healthy, stress-free learning environment.

\section{Materials and Methods}

The study surveyed all undergraduate Bachelor of Dental Surgery (BDS) students from the first year of their professional course to students in their final year at a prominent Australasian dental school. The BDS programme comprised a five-year curriculum commencing with a one-year general health-science programme (or equivalent) followed by four years of professional training in general dentistry. Hence, the students' second year of their degree (BDS2) is their first year of dental education; BDS3 is their second year of dental education and so on. 
IIUM Journal of Orofacial and Health Sciences (2021) 2(2): 107-119

The survey was a modified version of the

Dental Environment Stress (DES)

developed by Garbee et al (Garbee et al., questionnaire (Figure 1) originally

1980).

Question 1: What year group are you currently enrolled in?
a) BDS2
b) BDS3
c) BDS4
d) BDS5

Question 2: What is your gender?
a) Male
b) Female

Question 3: Are you a domestic or an international student?
a) Domestic
b) International

Question 4: What is your ethnicity?
a) European
b) Asian
c) Maori
d) Pacific Islander
e) Other: please state

Question 5: Are you a permanent resident of the country of study?
a) Yes
b) No

\section{Question 6: What is your age range?}
a) 19 or under
b) $20-23$
c) $24-27$
d) $28-31$
e) 32 or over

Question 7: Is English your first language?
a) Yes
b) No

For Question 8- 39 please indicate how stressful you are finding each item this year on a scale of 1-5 (note that if an item is not applicable to you, you will mark it "not at all stressful"):

$1=$ not at all stressful

$2=$ somewhat stressful

$3=$ quite stressful

$4=$ very stressful

$5=$ extremely stressful

Figure 1. Modified version of Dental Environment Stress (DES) questionnaire 


\section{Academic:}

Question 8: Amount of assigned classwork

Question 9: Difficulty of assigned classwork

Question 10: Competition for grades

Question 11: Examinations and grades

Question 12: Completing academic course requirements

Question 13: Fear of failing course or year

Question 14: Lack of time to complete assigned school-work

Question 15: Fear of being unable to catch up if behind

\section{Clinical and patient related:}

Question 16: Completing clinical course requirements

Question 17: Difficulty learning clinical procedures

Question 18: Difficulty in learning precision manual skills required in preclinical and laboratory work

Question 19: General clinical environment

Question 20: Responsibility for providing comprehensive patient care

Question 21: Patients' co-operation in their home-care

Question 22: Patients being late or not showing up for their appointments

Question 23: Working on patients' with dirty mouths

\section{Environmental:}

Question 24: Rules and regulations of the school

Question 25: Discrimination due to race, class status, ethnic group or gender

Question 26: Inconsistency of feedback from different teachers

Question 27: Receiving criticism from teachers

Figure 1. Modified version of Dental Environment Stress (DES) questionnaire (continued) 


\begin{tabular}{|l|}
\hline Personal: \\
\hline Question 28: Lack of confidence to be a successful dental student \\
\hline Question 29: Lack of confidence to be a successful dentist \\
\hline Question 30: Insecurity concerning ability to gain a job after graduation \\
\hline Question 31: Considering entering some other field of work \\
\hline Question 32: Financial concerns \\
\hline Question 33: Personal relationship problems \\
\hline Question 34: Lack of time for relaxation \\
\hline Question 35: Balancing dental school with leisure time \\
\hline Question 36: Balancing family with dental school commitments \\
\hline Question 37: Conflict with partner or family over career decision \\
\hline Question 38: Problems in living/home environment \\
\hline Question 39: Personal physical health (including mental health) \\
\hline Question 40: Do you have any further comments on stress at dental school: \\
\hline
\end{tabular}

Figure 1. Modified version of Dental Environment Stress (DES) questionnaire (continued).

The DES questionnaire wording was edited slightly to reflect the programme at the institution, and students from another professional oral health course at the same dental school, alongside two non-dental personnel, were asked to fill out the questionnaire. This pilot was undertaken to test the appropriateness and clarity of the items in the survey, and pilot respondents were asked to provide feedback. Questions that the pilot respondents found confusing or had difficulty understanding were either modified or removed from the inventory.

Subsequent to obtaining ethical approval (reference number D15/233) all undergraduate BDS students at the dental school were sent an email inviting them to complete the survey, during the second semester of 2015. The email contained a link to the anonymous electronic survey, which was hosted on the Qualtrics platform. The final modified version of the DES questionnaire consisted of 40 questions: seven collecting demographic information, one free text question, and 32 items related to various sources of stress, grouped into four broad categories/subscales: 1)
Academic (eight items) 2) Clinical and patient related (eight items) 3) Environmental (four items) and 4) Personal (twelve items). Students were asked to rate each item on a five-point Likert-type scale ranging from: 1) not at all stressful 2) somewhat stressful 3) quite stressful 4) very stressful and 5) extremely stressful. The data that support the findings of this study are available from the corresponding author upon reasonable request.

\section{Statistical analysis}

Statistical analysis was undertaken using IBM SPSS (version 22.0). Cronbach's alpha scores were calculated to determine internal consistency. The mean values for each student for each of the subscales (academic, clinical and patient responsibility, environmental and personal) as well as the overall self-reported stress values for each student were calculated. Non-parametric tests were performed to determine if there was evidence that the scores differed between the demographic variables. MannWhitney-U tests were performed to identify 
variation in binary variables such as gender, student with English as first language or student with a non-English speaking background (NESB), international or domestic student and permanent resident or non-permanent resident. Kruskal-Wallis tests were used to calculate variation in other demographic variables such as ethnicity, BDS year group and age. Where statistically significant differences were noted, the Dunn's test was performed to see which groups differed.

\section{Results}

\section{Demographics}

The demographic distribution of all participants (total 165 participants) is outlined in Table 1 . The demographic characteristics of participants was similar to the characteristics of the student body and represented an equal spread of respondents across all years of the professional programme.

Table 1. Demographic distribution of participants

\begin{tabular}{|c|c|}
\hline Demographic variable & n (\%) \\
\hline \multicolumn{2}{|l|}{ Gender } \\
\hline Male & $43(26.1)$ \\
\hline Female & $116(70.3)$ \\
\hline DNS & $6(3.6)$ \\
\hline \multicolumn{2}{|l|}{ Domestic/International } \\
\hline Domestic & $129(78.2)$ \\
\hline International & $30(18.3)$ \\
\hline DNS & $6(3.6)$ \\
\hline \multicolumn{2}{|l|}{ PR status } \\
\hline PR & $126(76.4)$ \\
\hline Non-PR & $32(19.4)$ \\
\hline DNS & $7(4.2)$ \\
\hline \multicolumn{2}{|l|}{ English language status } \\
\hline EAFL & $103(62.4)$ \\
\hline NESB & $53(32.1)$ \\
\hline DNS & $9(5.5)$ \\
\hline \multicolumn{2}{|l|}{ BDS year group } \\
\hline BDS2 & $43(26.1)$ \\
\hline BDS3 & $39(23.6)$ \\
\hline BDS4 & $40(24.2)$ \\
\hline BDS5 & $37(22.4)$ \\
\hline DNS & $6(3.6)$ \\
\hline \multicolumn{2}{|l|}{ Age } \\
\hline$<19$ & $14(8.5)$ \\
\hline $20-23$ & $125(75.8)$ \\
\hline $24-27$ & $14(8.5)$ \\
\hline $28-31$ & $2(1.2)$ \\
\hline$>32$ & $1(0.6)$ \\
\hline DNS & $9(5.5)$ \\
\hline \multicolumn{2}{|l|}{ Ethnicity } \\
\hline European & $51(30.9)$ \\
\hline Asian & $90(54.5)$ \\
\hline Maori & $11(6.7)$ \\
\hline Pacific Islander & $2(1.2)$ \\
\hline Other/DNS & $11(6.7)$ \\
\hline
\end{tabular}

DNS: did not state; PR: permanent resident; EAFL: English as first language; NESB: non-English speaking background; BDS: Bachelor of Dental Surgery. 
The Cronbach's alpha score for the total scale (i.e. all 32 items) was 0.91 whilst the Cronbach's alpha scores for the individual subscales were 0.79 (Academic), 0.73 (Clinical), 0.68 (Environmental) and 0.83 (Personal). This established construct validity for the total scale as well as the subscales. The only exception was the Environmental subscale as it was slightly below the desired level of 0.7 .

\section{Stressors}

The highest self-reported stressors for all students were in the academic subscale, as shown in Table 2. The mean reported academic stress score for BDS2 was $3.14 \pm$ 0.72 (SD) whilst the mean reported academic stress scores for BDS3, BDS4 and BDS5 were $3.01 \pm 0.68,3.14 \pm 0.67$ and 3.05 \pm 0.64 respectively. The subscale with the highest reported stress scores for the students overall was also the academic subscale (3.09 \pm 0.68$)$, followed by the clinical (2.71 \pm 0.70$)$, the environmental $(2.40 \pm 0.77)$ and then the personal $(2.37 \pm$ 0.68 ) subscales.

In the individual items, the highest reported stressor was "completing academic requirements" (in the academic subscale) scoring $3.54 \pm 1.16$; followed by "inconsistency of feedback from different teachers" (in the environmental subscale) scoring $3.46 \pm 1.14$ and "examinations and assessments" (also in the academic subscale) scoring $3.43 \pm 0.89$. The lowest scoring individual items included "conflict with partner or family over career decisions" and "discrimination due to race, class status, ethnic group or gender" scoring $1.53 \pm 1.10$ and $1.61 \pm 0.93$ respectively.

There was no significant difference ( $p=$ 0.386 ) in total perceived stress across the different year groups (Figure 2), the different age groups $(p=0.904)$ or across the different ethnicities $(\mathrm{p}=0.769)$ as identified by Kruskal-Wallis tests. There was also no significant difference in total perceived stress between the two genders $(p=0.220)$, between permanent residents and nonpermanent residents $(p=0.702)$, between domestic and international students $(\mathrm{p}=$ 0.603 ) or between students whose first language was English and students with a NESB $(p=0.171)$ as identified by MannWhitney-U tests. There was no significant difference in perceived stress for the above demographics in any of the subscales (academic, clinical and patient related, environmental and personal) except for: clinical stress between male and female students; environmental stress across the BDS year groups; and personal stress between students whose first language was English and students with a NESB.

The results indicate that there was a significant difference $(p=0.012)$ in perceived clinical stress between male and female students (Figure 3). Female students reported greater stress with a mean clinical stress score of $2.79 \pm 0.73$ whilst their male counterparts reported a mean clinical stress score of $2.48 \pm 0.57$.

Table 2. Mean stress scores (SD) per subscale for all Bachelor of Dental Surgery (BDS) year groups

\begin{tabular}{lllll}
\multirow{2}{*}{ BDS year group } & \multicolumn{3}{c}{ Mean (SD) } \\
\cline { 2 - 5 } & Academic & Clinical & Environmental & Personal \\
\hline 2 & $3.14(0.72)$ & $2.65(0.93)$ & $2.11(0.68)$ & $2.27(0.69)$ \\
3 & $3.01(0.68)$ & $2.82(0.73)$ & $2.60(0.85)$ & $2.42(0.69)$ \\
4 & $3.14(0.67)$ & $2.61(0.54)$ & $2.37(0.72)$ & $2.40(0.65)$ \\
5 & $3.05(0.64)$ & $2.77(0.51)$ & $2.55(0.75)$ & $2.41(0.73)$ \\
Total & $3.09(0.68)$ & $2.71(0.77)$ & $2.40(0.77)$ & $2.37(0.68)$ \\
\hline
\end{tabular}




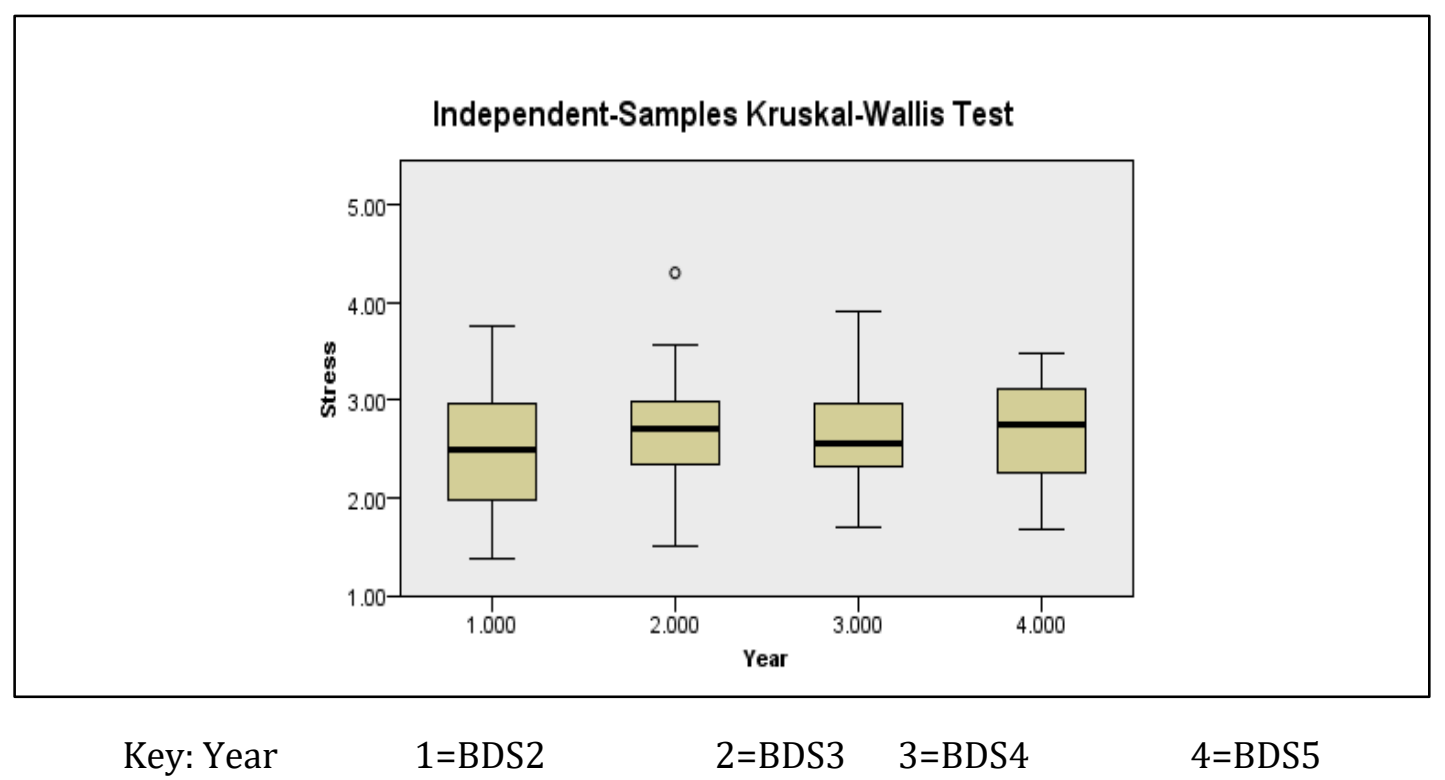

Figure 2. Total stress scores for all Bachelor of Dental Surgery (BDS) year groups

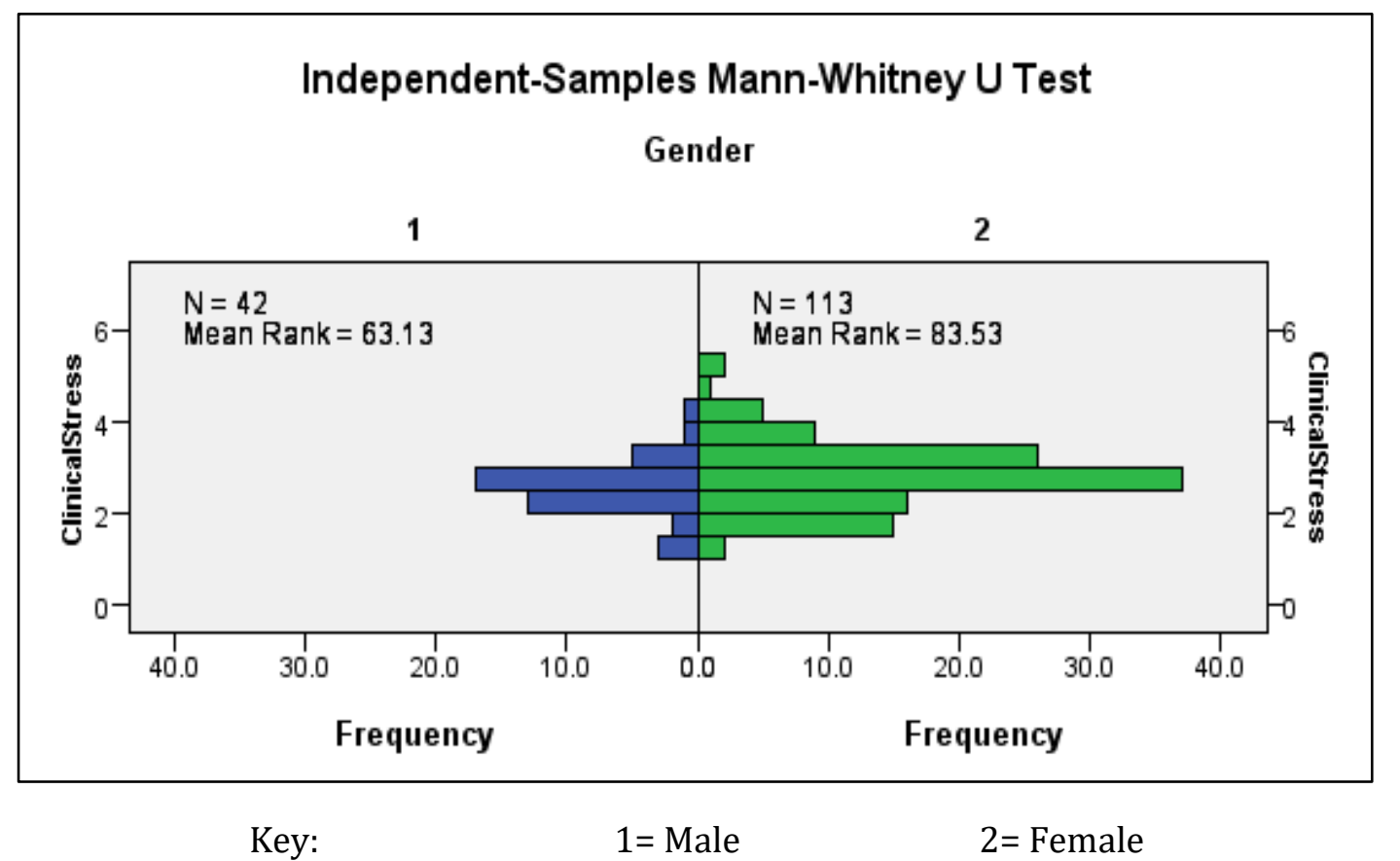

Figure 3. Clinical stress scores by gender

There was also a significant difference $(\mathrm{p}=$ 0.025 ) in perceived environmental stress between the different BDS year groups (Figure 4). BDS2 reported a mean environmental stress score of $2.11 \pm 0.68$ whilst BDS year groups 3, 4 and 5 reported mean environmental stress scores of $2.60 \pm$ $0.85, \quad 2.37 \pm 0.72$ and $2.55 \pm 0.75$ respectively. There was a statistically significant difference in perceived environmental stress between BDS2 and BDS3 ( $\mathrm{p}=0.037)$ but no statistically significant difference between any of the other year groups. There was also a large, although not statistically significant difference $\quad(p=0.073)$ in perceived environmental stress between BDS2 and BDS5 students. 
Lastly, there was a significant difference $(\mathrm{p}=$ 0.034 ) in perceived personal stress between students whose first language was English and students with a NESB (Figure 5). Surprisingly perhaps, the students with a
NESB reported lower personal stress with a mean score of $2.20 \pm 0.59$ compared with students whose first language was English who reported a mean score of $2.50 \pm 0.71$.

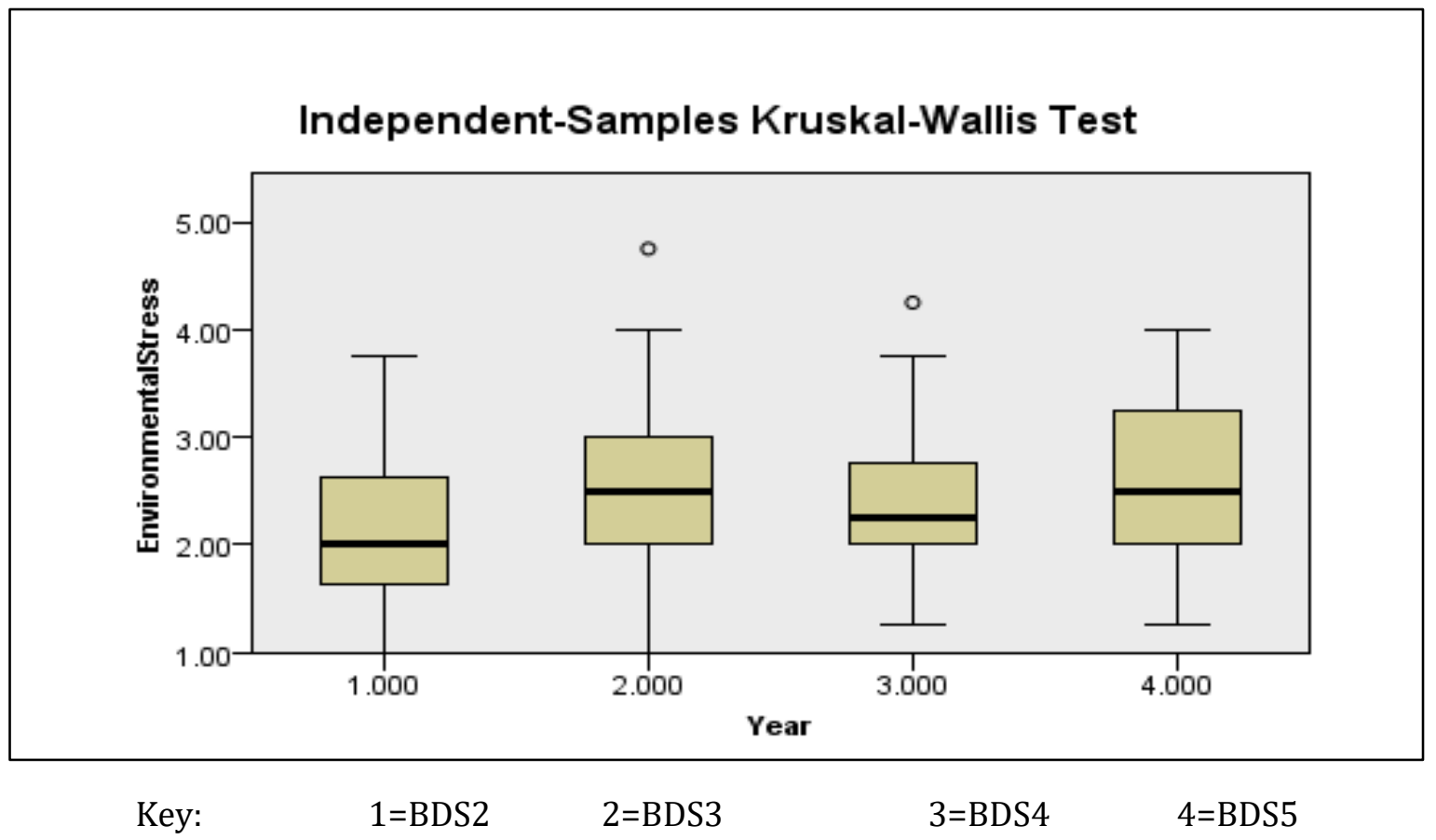

Figure 4. Environmental stress scores by Bachelor of Dental Surgery (BDS) year group

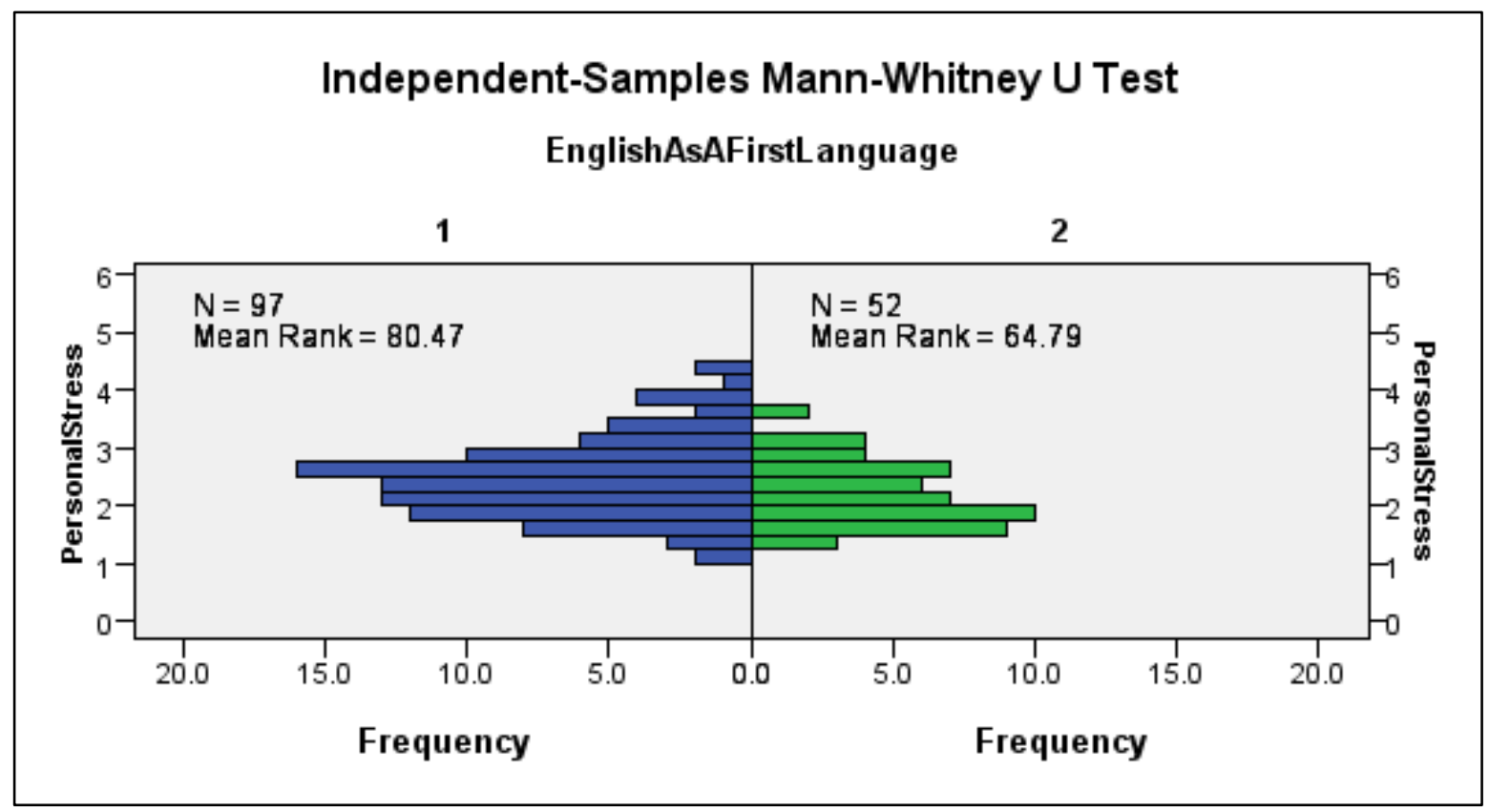

Key: $\quad 1=$ English as first language $\quad 2=$ non-English speaking background

Figure 5. Personal stress scores for students with English as a first language vs non-English speaking background 


\section{Discussion}

In the past three decades stress amongst undergraduate dental students has been highlighted as a major concern for dental educators (Alzahem et al., 2011). Student stress may hinder performance, as well as the well-being of parties involved, hence much research has been conducted to shed light on this complex issue (Birks et al., 2009; Kumar et al., 2009).

Numerous studies at various dental schools internationally have reported that students' highest stressors have related to academic factors including examinations and grades, and assigned workload (Abu-Ghazaleh et al., 2011; Al-Sowygh, 2013; Fonseca et al., 2013; Kumar et al., 2009; Muirhead \& Locker, 2008; Polychronopoulou \& Divaris, 2009). Consistent with these findings the current study found that the subscale with the highest perceived stress score was the academic subscale. The items "completing academic requirements" and "examinations and assessments" in particular were marked as highly stressful by students. This is not surprising as assessments and academic requirements in higher education are necessarily stressful due to their high stakes nature, and dentistry is known to be a particularly challenging academic field (Fonseca et al., 2013). Considering these findings, thought may need to be given regarding whether this is something that needs to be addressed.

Another item that the students marked as highly stressful was "Inconsistency of feedback from different teachers" (from the environmental subscale). This finding is also consistent with findings from a previous study which report "improper feedback from tutors" as a major stressor (Al-Sowygh, 2013). The dental education literature contains multiple references to the importance of feedback in dental education. Research at the institution at which this study was undertaken found that feedback practices in the clinical setting were central to students' learning and outcomes (Adam et al., 2019; Ebbeling et al., 2018). Similarly, a study by Pine and McGoldrick (Pine \&
McGoldrick, 2000) in the United Kingdom highlighted inconsistencies in teaching as an issue. The study found that teaching was adequate in most areas of the concerning dental school; however, there were inadequacies in clinical application of a theoretical basis. A study in Greece (Kossioni et al., 2012) also reported problems with the curriculum and teaching practices, however, the authors did highlight the multiple stressors that dental educators face on a daily basis. Considering these findings, students' stress levels may be reduced if consistency of feedback in the clinical learning environment is ensured.

Differences according to gender in selfreported clinical and patient related stress levels were evident in the data analysis. The subject of gender differences in perceived stress in the dental learning environment is a controversial topic with studies reporting conflicting findings. Some studies note that females report greater levels of stress than male students (Abu-Ghazaleh et al., 2011; AlSowygh, 2013). Some of these studies specifically indicate that females report higher levels of stress in relation to clinical factors or higher levels of stress are reported by females in clinical years of study (Pau \& Croucher, 2003; Polychronopoulou \& Divaris, 2005). Conversely, other studies indicate that there are no gender differences in perceived stress (Fonseca et al., 2013; Kossioni et al., 2012; Kumar et al., 2009) and that participants' gender does not influence the likelihood of burnout (Mafla et al., 2015). One explanation for these discrepancies may be that female students are more likely than male students to report their perceived stresses (Pau \& Croucher, 2003).

Although students' clinic and patient related stress scores revealed statistically significant differences between male and female respondents, the current study did not find a statistically significant difference in overall reported stress between male and female students. These findings indicate that some female students may require greater support in the clinical setting than male students, however, it should be taken into account that male students may also benefit from increased support. One reason that this 
may not be apparent in the data is possible under-reporting by the male cohort (Pau \& Croucher, 2003).

Another notable finding in the current study was the significant difference in perceived environmental stress between BDS2 and BDS3 students. The second year of the dental education programme (BDS3) was when students were first introduced to the patient clinical environment. In BDS2, students' clinical experiences were limited to the simulation environment. It is, therefore, unsurprising that BDS3 students reported significantly more environmental stress than BDS2 students. This finding is consistent with previous studies that reported students found the transition from preclinical to clinical years stressful (AlSowygh, 2013; Pau \& Croucher, 2003). Interestingly, in the current study there were no significant differences between BDS2 students' and BDS3 students' clinic and patient related stress, or their academic stress. This indicates that interventions designed to ease students' transition into the clinical environment could be beneficial towards reducing students' stress in relation to treating patients.

Lastly, the statistically significant difference $(p=0.034)$ in perceived personal stress between students whose first language was English and students with a NESB was unexpected. Contrary to our expectations that NESB students would report higher stress, they reported less personal stress. One explanation for this may be that since these students were able to study a subject as challenging as dentistry in a language different to their native-tongue, they may have developed more resilience than their peers and were therefore better able to cope with other stresses (Wang, 2009). It should be noted however, that previous research has reported greater stress levels in students with "poor command of English" (AlSowygh, 2013).

As has been mentioned previously, the stresses placed on dental students have been noted in the literature for the last three decades (Fonseca et al., 2013). However, ways in which dental students' stress could be reduced have not been fully explored. Furthermore, the amount of research into dental students' stress indicates a perception that stress among students is a bad thing. This perception does not take into account that stress is a broad term, there are many ways to define it and even more ways that it may be perceived (Elani et al., 2014). The multi-factorial nature of stress makes its assessment difficult (Al-Sowygh, 2013), particularly with regard to determining if the stress is enabling or inhibiting performance. Hence, deciding how to proceed on the basis of students' stress is problematic.

Although too much stress can impede performance, it can also work as a driver towards success. Stress does have some positive outcomes, such as personal transformation and growth. A review by Folkman and Moskowitz (Folkman \& Moskowitz, 2000) outlined three mechanisms that enable stress to bring out positive emotion: a) positive reappraisal (focusing on the good); b) problem focused coping (thoughts and behaviours to solve the source of distress); and c) creation of positive events (infusing ordinary events with a positive meaning). Keeping these ideas in mind, the issue with the dental learning environment may not necessarily be stress itself, but rather the coping mechanisms and resilience of the students involved.

Strategies suggested in the literature for the management of students' stress include increasing study groups and interactive education; changes to assessment practices (Polychronopoulou \& Divaris, 2005); and establishing student advisors and councillors. Similarly, a faculty advising system has also been shown to have a positive impact on reducing students' stress (Fonseca et al., 2013; Kumar et al., 2009; Polychronopoulou \& Divaris, 2005). The dental school where this study was undertaken has an established student support office; however, it is possible that students are not taking advantage of this. It was beyond the scope of this research to investigate what strategies students were undertaking to reduce their stress, or to find 
out what the students thought the school could do to reduce their stress levels. Further research could be conducted to ascertain whether there is a link between students' reported stress levels and their use of such services.

Another concept that is popular in the literature is the relationship between emotional intelligence (EI) and perceived stress. EI may be defined in terms of four characteristics "perception, appraisal and expression of emotion; emotional facilitation of thinking; understanding, analysing and employing emotional language; and reflective regulation of emotions"(Pau \& Croucher, 2003). Studies show that students with higher EI are less likely to report perceived stressors (Pau et al., 2007; Pau \& Croucher, 2003). There is also evidence for higher EI leading to professional competence in medical education (Pau et al., 2007). These findings indicate that a possible strategy may be to introduce a more rigorous EI test for entry into the BDS professional course. A suggestion by Pau (Pau et al., 2007) is to limit entry into the programme to students who already possess a higher education qualification. This was recommended on the basis that graduates are more likely to have a higher EI and would therefore be better able to cope with the stresses of dental education.

The cross-sectional nature of the current study means that the differences between years may have been pre-existing, therefore longitudinal changes cannot be determined. Secondly, bias may have been present as the questionnaire was self-administered. The response rate of $52.5 \%$, although satisfactory, is not substantial and might be considered another limitation. However, the results of this study do add to our understanding of dental students' stress within Australasia, and possibly worldwide, and can help with designing more targeted interventions depending on the identified stressors.

\section{Conclusion}

The results of this study show that students entering their first clinical year of dental education (working on patients) report higher stressors than preclinical students or students in later stages of their programme. Students from all years of their programme reported high amounts of stress in relation to completing academic requirement. These finding indicate that interventions designed to help students manage their stress or resilience in relation to academic requirements might be beneficial, along with increased support for students entering their first year of clinical education. In addition, female students reported higher levels of stress in the clinical setting than male students reported. However, this study, consistent with other studies on stressors in dental education, did not examine whether the students' stress levels were productive or counter-productive. Determining whether the students' stress is enabling them or is acting as a barrier to their success will inform whether interventions to reduce students' stress would be beneficial.

\section{Acknowledgements}

The authors would like to acknowledge $\mathrm{Mr}$ Andrew Gray who was a tremendous help with the statistical analysis of the obtained data.

\section{Conflict of interest}

The authors have no financial interests or conflicts of interest to declare.

\section{References}

Abu-Ghazaleh, S. B., Rajab, L. D., \& Sonbol, H. N. (2011). Psychological stress among dental students at the University of Jordan. Journal of Dental Education, 75(8), 1107-1114.

Adam, L. A., Oranje, J., Rich, A. M., \& Meldrum, A. (2019). Advancing dental education: feedback processes in the clinical learning environment. Journal of the Royal Society of New Zealand, 1-14.

Al-Sowygh, Z. H. (2013). Academic distress, perceived stress and coping strategies among dental students in Saudi Arabia. The Saudi Dental Journal, 25(3), 97-105.

Alzahem, A., Van der Molen, H., Alaujan, A., Schmidt, H., \& Zamakhshary, M. (2011). Stress amongst dental 
students: a systematic review. European Journal of Dental Education, 15(1), 8-18.

Birks, Y., McKendree, J., \& Watt, I. (2009). Emotional intelligence and perceived stress in healthcare students: a multi-institutional, multi-professional survey. BMC Medical Education, 9(1), 61.

Ebbeling, S., Adam, L., Meldrum, A., Rich, A., McLean, A., \& Aitken, W. (2018). Oral health and dental students' perceptions of their clinical learning environment: A focus group study. Journal of Dental Education, 82(10), 1036-1042.

Elani, H. W., Allison, P. J., Kumar, R. A., Mancini, L., Lambrou, A., \& Bedos, C. (2014). A systematic review of stress in dental students. Journal of Dental Education, 78(2), 226-242.

Fink, G. (2016). Stress: concepts, definition and history. Change.

Folkman, S., \& Moskowitz, J. T. (2000). Stress, positive emotion, and coping. Current Directions in Psychological Science, 9(4), 115-118.

Fonseca, J., Divaris, K., Villalba, S., Pizarro, S., Fernandez, M., Codjambassis, A. et al. (2013). Perceived sources of stress amongst $\mathrm{C}$ hilean and $\mathrm{A}$ rgentinean dental students. European Journal of Dental Education, 17(1), 30-38.

Garbee, W. H., Zucker, S. B., \& Selby, G. R. (1980). Perceived sources of stress among dental students. The Journal of the American Dental Association, 100(6), 853-857.

Harikiran, A., Srinagesh, J., Nagesh, K., \& Sajudeen, N. (2012). Perceived sources of stress amongst final year dental under graduate students in a dental teaching institution at Bangalore, India: A cross sectional study. Indian Journal of Dental Research, 23(3), 331.

Kossioni, A. E., Varela, R., Ekonomu, I., Lyrakos, G., \& Dimoliatis, I. (2012). Students' perceptions of the educational environment in a Greek Dental School, as measured by DREEM. European Journal of Dental Education, 16(1), e73-e78.
Kumar, S., Dagli, R., Mathur, A., Jain, M., Prabu, D., \& Kulkarni, S. (2009). Perceived sources of stress amongst Indian dental students. European Journal of Dental Education, 13(1), 39-45.

Mafla, A., Villa-Torres, L., Polychronopoulou, A., Polanco, H., Moreno-Juvinao, V., Parra-Galvis, D. et al. (2015). Burnout prevalence and correlates amongst Colombian dental students: the STRESSCODE study. European Journal of Dental Education, 19(4), 242-250.

Morse, Z., \& Dravo, U. (2007). Stress levels of dental students at the Fiji School of Medicine. European Journal of Dental Education, 11(2), 99-103.

Muirhead, V., \& Locker, D. (2008). Canadian dental students' perceptions of stress and social support. European Journal of Dental Education, 12(3), 144148.

Pau, A., Rowland, M. L., Naidoo, S., AbdulKadir, R., Makrynika, E., Moraru, R. et al. (2007). Emotional intelligence and perceived stress in dental undergraduates: a multinational survey. Journal of Dental Education, 71(2), 197-204.

Pau, A. K., \& Croucher, R. (2003). Emotional intelligence and perceived stress in dental undergraduates. Journal of Dental Education, 67(9), 1023-1028.

Pine, C. M., \& McGoldrick, P. M. (2000). Application of behavioural sciences teaching by UK dental undergraduates. European Journal of Dental Education, 4(2), 49-56.

Polychronopoulou, A., \& Divaris, K. (2005). Perceived sources of stress among Greek dental students. Journal of Dental Education, 69(6), 687-692.

Polychronopoulou, A., \& Divaris, K. (2009). Dental students' perceived sources of stress: a multicountry study. Journal of Dental Education, 73(5), 631-639.

Wang, J. (2009). A study of resiliency characteristics in the adjustment of international graduate students at American universities. Journal of Studies in International Education, 13(1), 22-45. 